\title{
A Study of Fecal Calprotectin in Obese Children and Adults
}

\author{
Shin Young Park', Woo Jin Kim,** \\ 'Department of Clinical Pathology, Cheju Halla University, Jeju; ${ }^{2}$ Department of Laboratory Medicine, Cheju Halla General Hospital, Jeju, Korea
}

Background: Obesity is a complex, medical condition causally contributing to many chronic diseases and a number of efforts have been made to find the associated markers for novel prevention and treatment of obesity. Our study was to evaluate the relationship between gut immune response and obesity and overweight with use of fecal calprotectin (FC) both in adult and children groups.

Methods: Fecal samples were obtained from 74 subjects: 14 non-obese and overweight children (PN), 13 obese and overweight children (PO), 20 non-obese and overweight adults (AN), and 27 obese and overweight adults (AO). FC was measured using a commercial Legend Max quantitative enzyme-linked immunosorbent assay (BioLegend). Mann-Whitney U-test was used for statistical analysis.

Results: Median FC concentration was $7.9 \mu \mathrm{g} / \mathrm{g}$ (range, 1.9-28.9 $\mu \mathrm{g} / \mathrm{g}$ ) for PN, $5.0 \mu \mathrm{g} / \mathrm{g}$ (range, 2.6-29.6 $\mu \mathrm{g} / \mathrm{g}$ ) for PO, $9.5 \mu \mathrm{g} / \mathrm{g}$ (range, $0.8-28.9 \mu \mathrm{g} / \mathrm{g}$ ) for AN, and $10.0 \mu \mathrm{g} / \mathrm{g}$ (range, 1.6-25.6 $\mu \mathrm{g} / \mathrm{g}$ ) for AO, respectively. In both adults and children age groups, the FC showed no statistically significant difference between $A O$ and $A N$ or PO and PN. However, FC showed statistically significant difference $(P<0.05)$ between $\mathrm{AO}$ and $\mathrm{PO}$ while not significant between $\mathrm{AN}$ and $\mathrm{PN}$.

Conclusion: $\mathrm{FC}$ level in $\mathrm{AO}$ was significantly higher than that in $\mathrm{PO}$, suggestive of different pathophysiologic mechanism between children obesity and adults obesity.

Key words: Obesity, Leukocyte L1 antigen complex, Immunity, Mucosal
Received June 24, 2018

Reviewed July 19, 2018

Accepted September 6, 2018

*Corresponding author Woo Jin Kim

(iD) https://orcid.org/0000-0003-4999-1493

Department of Laboratory Medicine, Cheju Halla General Hospital, 65 Doryeong-ro, Jeju 63127, Korea Tel: +82-64-740-5256 Fax: +82-64-743-3110 E-mail: oojinkim@hanmail.net

\section{INTRODUCTION}

Obesity contribute substantially to mortality and are major risk factors for many chronic diseases including diabetes, vascular disease, and cancer. ${ }^{1}$ Obesity and overweight in both children and adults continues to rise globally. ${ }^{2} \mathrm{~A}$ number of efforts have been made to find the associated markers in the quest for novel prevention and treatment of obesity. The studied markers include adipocytic markers (adipokines: leptin, adiponectin) ${ }^{3}$, hepatic or pancreatic markers (insulin-like growth factor $1, \mathrm{C}$-reactive protein [CRP], insulin $)^{4}$, gastrointestinal markers (ghrelin, cholecystokinin). ${ }^{5}$

Attention to intestinal immunity has been grown in the patho- genesis of various diseases. This includes the observation that the gut inflammatory profile in patients with type 1 diabetes is distinctive compared with healthy control subjects and gut inflammatory disease controls. ${ }^{6}$ Additional reports showed that the colon mucosa from the patients with rheumatoid arthritis (RA) expressed unique three peptides involved in citrullination, an inflammation-dependent process, which could contribute to the onset of RA. ${ }^{7}$ It is well known that neutrophils and monocytes in gut release calprotectin which is one of the key role players in gut immunity. ${ }^{8,9}$ Our study was to evaluate the relationship between gut immune response and obesity and overweight with use of fecal calprotectin (FC) both in adult and children groups. 
Table 1. Demographic characteristics of the study population

\begin{tabular}{|c|c|c|c|c|c|c|}
\hline Variable & $P N(n=14)$ & $\mathrm{PO}(\mathrm{n}=13)$ & $P$ & AN $(n=20)$ & $\mathrm{AO}(\mathrm{n}=27)$ & $P$ \\
\hline Age (yr) & $9.6 \pm 3.2(3.1-14.5)$ & $10.2 \pm 3.5(6.36-17.5)$ & 0.522 & $47.6 \pm 11.8(22.7-63.6)$ & $46.1 \pm 11.1(25.7-62.2)$ & 0.692 \\
\hline Sex (male:female) & $6: 8$ & $8: 5$ & 0.351 & 1:19 & $12: 15$ & 0.002 \\
\hline Height (cm) & $140.7 \pm 22.6$ & $143.8 \pm 16.6$ & 0.687 & $159.6 \pm 7.4$ & $166.0 \pm 11.8$ & 0.037 \\
\hline Height (Z-score) & $0.5 \pm 0.7$ & $0.4 \pm 1.1$ & 0.914 & NA & NA & NA \\
\hline Weight (kg) & $32.6 \pm 12.6$ & $51.0 \pm 16.1$ & 0.003 & $50.5 \pm 7.4$ & $73.2 \pm 9.9$ & $<0.001$ \\
\hline Weight (Z-score) & $-0.6 \pm 0.8$ & $1.6 \pm 0.9$ & $<0.001$ & NA & NA & NA \\
\hline $\mathrm{BMI}\left(\mathrm{kg} / \mathrm{m}^{2}\right)$ & $15.9 \pm 2.4$ & $23.9 \pm 3.0$ & $<0.001$ & $19.7 \pm 1.2$ & $26.6 \pm 2.2$ & $<0.001$ \\
\hline BMI (Z-score) & $-1.1 \pm 1.1$ & $2.0 \pm 0.8$ & $<0.001$ & NA & NA & NA \\
\hline
\end{tabular}

Values are presented as mean $\pm \mathrm{SD}$ (range) or mean $\pm \mathrm{SD}$.

PN, non-obese and overweight children; PO, obese and overweight children; AN, non-obese and overweight adults; AO, obese and overweight adults; NA, not applicable; BMI, body mass index; SD, standard deviation.

\section{METHODS}

\section{Subjects}

In the present study, fecal samples were obtained from 74 subjects: 14 non-obese and overweight children (PN), 13 obese and overweight children (PO), 20 non-obese and overweight adults (AN), and 27 obese and overweight adults (AO) (Table 1). Written informed consent was obtained from the subjects or their guardians. Diagnosis was based on the World Health Organization criteria in Asians as those with a BMI $\geq 23$ and $\geq 25 \mathrm{~kg} / \mathrm{m}^{2}$ for overweight and obese adult ${ }^{10}$ and criteria of Korea Centers for Disease Control Prevention as those with BMI $\geq 85$ th and $\geq 95$ th percentiles for overweight and obese children. ${ }^{11}$ The subjects in the study met the exclusion criteria, based on a study of factors affecting levels of $\mathrm{FC}^{12}$, which are as follows: no history of colorectal or systemic inflammatory condition, proton pump inhibitor use, regular $(\geq 4$ doses per week) use of nonsteroidal anti-inflammatory drugs, smoking or alcohol. The study was approved by the Ethical Committee of Cheju Halla General Hospital (No. CHHIRB-2015-L06-01).

\section{Fecal calprotectin}

Subjects provided a single fecal sample for calprotectin measurement. Fecal samples were frozen on receipt at $-80^{\circ} \mathrm{C}$ for further analysis. Before quantitative analysis, the frozen fecal samples were kept at room temperature (RT) for 30 minutes. After thawing, a single 100-mg aliquot was suspended in $1 \mathrm{~mL}$ of fecal extraction buffer (0.1 M Tris buffered saline with Tween 20, pH 8.0 [MB Cell, Los Angeles, CA, USA] with $0.5 \%$ bovine serum albumin, $0.15 \mathrm{M}$
$\mathrm{NaCl}, 10 \mathrm{mM} \mathrm{CaCl}$ ), and homogenized for 5 minutes with an vortex mixer (Scientific Industries, Bohemia, NY, USA). The homogenates were centrifuged for 15 minutes at $10,000 \mathrm{~g}$ at RT. The upper portion of the supernatants were pipette off, frozen, and stored at $-80^{\circ} \mathrm{C}$ until quantitation by enzyme-linked immunosorbent assay.

FC was measured using a commercial Legend Max quantitative assay (BioLegend, San Diego, CA, USA). In details, the frozen fecal extracts were thawed and diluted 1:10 in the assay buffer. Standards and diluted samples $(50 \mu \mathrm{L})$ were added to the plates which were covered and incubated at RT for 1 hour on a plate while shaking at $200 \mathrm{rpm}$. The wells were washed four times with wash buffer and $100 \mu \mathrm{L}$ of human MRP8/14 detection antibody solution was added to each well, the plate covered, and incubated at RT for $30 \mathrm{~min}$ utes while shaking. Thereafter the wells were washed five times, $100 \mu \mathrm{L}$ of substrate solution was added. The reaction was stopped by adding $100 \mu \mathrm{L}$ of stop solution and the absorbance was read at both $450 \mathrm{~nm}$ and $570 \mathrm{~nm}$ using PowerWave XS2 Microplate spectrophotometer (BioTek, Winooski, VT, USA). The absorbance at $570 \mathrm{~nm}$ was subtracted from the absorbance at $450 \mathrm{~nm}$. Calprotectin was expressed in micrograms per gram of fecal sample.

\section{Statistics}

Data were analyzed using the GraphPad Prism (GraphPad Software, La Jolla, CA, USA) statistical software package. Calprotectin values were presented as mean \pm standard deviation, median and ranges. A Student $t$-test was used to evaluate the significance of the mean differences of demographic characteristics between PN, PO 
Table 2. Descriptive statistics of fecal calprotectin levels in four groups

\begin{tabular}{lcc}
\hline Group & Mean $\pm S D(\mu \mathrm{g} / \mathrm{g})$ & Median $($ range, $\mu \mathrm{g} / \mathrm{g})$ \\
\hline PN $(n=14)$ & $11.9 \pm 9.6$ & $7.9(1.9-28.9)$ \\
PO $(n=13)$ & $7.8 \pm 7.8$ & $5.0(2.6-29.6)$ \\
AN $(n=20)$ & $11.6 \pm 9.7$ & $9.5(0.8-28.9)$ \\
AO $(n=27)$ & $12.7 \pm 7.5$ & $10.0(1.6-25.6)$ \\
\hline
\end{tabular}

$\mathrm{SD}$, standard deviation; PN, non-obese and overweight children; PO, obese and overweight children; AN, non-obese and overweight adults; $\mathrm{AO}$, obese and overweight adults.

and AN, AO groups. Mann-Whitney $U$-tests were performed to compare FC between $\mathrm{PN}, \mathrm{PO}, \mathrm{AN}$, and $\mathrm{AO}$ groups. The correlation between FC levels and BMI in children and/or adult was analyzed with Pearson or Spearman correlation analyses. All significant values were two-sided and $P<0.05$ was considered to indicate a statistically significant difference.

\section{RESULTS}

Median FC concentration was $7.9 \mu \mathrm{g} / \mathrm{g}$ (range, 1.9-28.9 $\mu \mathrm{g} / \mathrm{g}$ ) for PN, $5.0 \mu \mathrm{g} / \mathrm{g}$ (range, 2.6-29.6 $\mu \mathrm{g} / \mathrm{g}$ ) for PO, $9.5 \mu \mathrm{g} / \mathrm{g}$ (range, 0.8-28.9 $\mu \mathrm{g} / \mathrm{g}$ ) for $\mathrm{AN}$, and $10.0 \mu \mathrm{g} / \mathrm{g}$ (range, 1.6-25.6 $\mu \mathrm{g} / \mathrm{g}$ ) for AO, respectively (Table 2 ). In both adult and children age groups, the FC showed no statistically significant difference between $\mathrm{AO}$ and $\mathrm{AN}$ or $\mathrm{PO}$ and PN. However, in detail, FC was higher in $\mathrm{AO}$ than in AN while in children, the FC was higher in PN than in PO though statistically not significant. FC showed statistically significant difference between $\mathrm{AO}$ and PO while FC showed no significant difference between AN and PN (Fig. 1). The correlation analyses showed no significant correlation between FC and BMI in child and/or adult groups.

\section{DISCUSSION}

Growing research suggests that obesity is not a simple phenomenon form improper diet and lifestyle, but a multi-factorial medical condition beyond individuals' control. ${ }^{13}$ Among the factors, growing evidence suggests inflammatory links with obesity. Tumor necrosis factor (TNF)- $\alpha$ expression in the adipose tissue was reported to be increased in obese humans several decades ago. ${ }^{14}$ Recent mice experiments showed that only TNF- $\alpha$ among multiple inflammatory cytokines was upregulated by high fat diets specifically in the

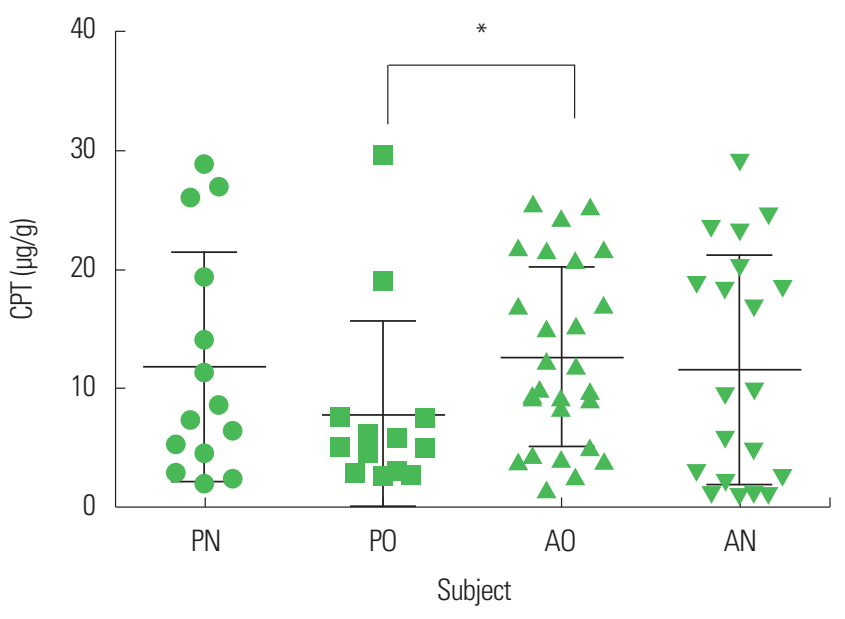

Figure 1. Scatter plots of fecal calprotectin (FC) levels in four groups. Comparison of FC levels between non-obese and overweight children (PN), obese and overweight children (PO), obese and overweight adults (AO), and non-obese and overweight adults (AN). The data were presented as mean \pm standard error of mean. MannWhitney U-test was used for statistical analysis. ${ }^{*} P<0.05$. CPT, calprotectin.

ileum before weight gain and increase in fat mass. ${ }^{15}$

Our results in adult groups are consistent with the reports by Mendall et al. ${ }^{12}$ In a middle-aged healthy general population sample of 300 subjects (range, 50-70 years), they reported that the relationship of FC with BMI was not statistically significant, but the mean of FC in obese and overweight adult (BMI, $25.7-41.2 \mathrm{~kg} / \mathrm{m}^{2}$ ) was higher than that in non-obese and overweight (BMI, 17.6-25.6 kg/m²). ${ }^{16}$ What does it suggest that there is statistically not significant but difference between obese and overweight and non-obese and overweight groups? Recent report may be a clue to this matter. Verdam et al. ${ }^{17}$ studied FC and gut microbiota composition of 28 adult (BMI, 18.6-60.3 kg/m²) and found interesting finding that FC was only detectable in obese subjects with an obese pattern of microbiota. In contrary to adult groups, case control studies in pediatric groups are rare and a few reports about FC levels studied only in obese children. Spagnuolo et al. ${ }^{18}$ studied 35 children with severe obesity (BMI >95\%) and found that FC was increased only in 47\% patients while CRP in $73.5 \%$. Taken together, larger scale study and stratification based on other indicators such as gut microbiota composition than BMI is warranted.

The other interest finding in our result is that FC showed statistically significant difference between obese and overweight adult and obese and overweight children while FC showed no statistically significant difference between non-obese and overweight adults 
and non-obese and overweight children.

Calprotectin is secreted extracellularly from stimulated neutrophils and the FC levels of healthy children exhibit a downward trend with increasing age and reach the adult level by the age of four. ${ }^{19,20}$ This finding is consistent with recent FC study in healthy children aged less than 4 years in South Korea. ${ }^{21}$ The children were divided into six age groups and the median FC values was $135 \mu \mathrm{g} / \mathrm{g}$ in 7-12 months group, $65 \mu \mathrm{g} / \mathrm{g}$ in $13-18$ months group, $55 \mu \mathrm{g} / \mathrm{g}$ in 19-24 months group, $40 \mu \mathrm{g} / \mathrm{g}$ in 25-30 months group, $21 \mu \mathrm{g} / \mathrm{g}$ in $31-36$ months group, and $12 \mu \mathrm{g} / \mathrm{g}$ in $37-48$ months group. Why FC varies with age remains uncertain, but several research papers may be clues to this question and significant FC difference between $\mathrm{AO}$ and PO in our result. Lee et al. ${ }^{22}$ studied FC levels of 133 healthy infants aged 0-6 months according to feeding mode and found that the mean FC values for breast-fed infants $(354.67 \mu \mathrm{g} / \mathrm{g})$ was higher than formula-fed infants $(149.44 \mu \mathrm{g} / \mathrm{g}, P<0.001)$.

Formula-fed boys (38.6\%) were significantly more likely to be obese than breast-fed boys $(23.4 \%, P<0.01) .{ }^{23}$ The ontogeny study of the immune system by type of infant feeding showed that blood cells of lymphoid lineage did not change significantly in frequencies or composition from 1.5 to 6 months of age in breast-fed infants. In contrast, formula-fed infants displayed an ongoing maturation of adaptive immunity cells and a delayed recruitment of innate immunity cells as compared with breast-fed infants. ${ }^{24}$ Obesity is a well-established risk factor for venous thromboembolism in adults in contrary to children. ${ }^{25}$ Taken these together, our finding and the above reports suggest different pathophysiologic background between adult obesity and children obesity. One possible explanation involves adaptive immunity behind children obesity and innate immunity behind adult obesity, and it warrants further research to elucidate exact mechanism and associated links between host gut immunity and obesity as inflammation. In conclusion, FC level in AO was significantly higher than that in PO, suggestive of different pathophysiologic mechanism between childhood and adulthood obesity. Further study is needed.

\section{CONFLICTS OF INTEREST}

The authors declare no conflict of interest.

\section{REFERENCES}

1. Lim S. Journal of Obesity \& Metabolic Syndrome: a new international journal targeting the pathophysiology and treatment of obesity and metabolic syndrome. J Obes Metab Syndr 2017;26:81-3.

2. World Health Organization. Fact sheet on obesity and overweight [Internet]. Geneva: World Health Organization; 2018 [cited 2018 Oct 16]. http://www.who.int/mediacentre/factsheets/fs311/en/

3. Engin A. The pathogenesis of obesity-associated adipose tissue inflammation. Adv Exp Med Biol 2017;960:221-45.

4. Lewitt MS, Dent MS, Hall K. The insulin-like growth factor system in obesity, insulin resistance and type 2 diabetes mellitus. J Clin Med 2014;3:1561-74.

5. Prinz P, Stengel A. Control of food intake by gastrointestinal peptides: mechanisms of action and possible modulation in the treatment of obesity. J Neurogastroenterol Motil 2017;23: 180-96.

6. Pellegrini S, Sordi V, Bolla AM, Saita D, Ferrarese R, Canducci F, et al. Duodenal mucosa of patients with type 1 diabetes shows distinctive inflammatory profile and microbiota. J Clin Endocrinol Metab 2017;102:1468-77.

7. Bennike TB, Ellingsen T, Glerup H, Bonderup OK, Carlsen TG, Meyer MK, et al. Proteome analysis of rheumatoid arthritis gut mucosa. J Proteome Res 2017;16:346-54.

8. Lopez RN, Leach ST, Lemberg DA, Duvoisin G, Gearry RB, Day AS. Fecal biomarkers in inflammatory bowel disease. J Gastroenterol Hepatol 2017;32:577-82.

9. Damo SM, Kehl-Fie TE, Sugitani N, Holt ME, Rathi S, Murphy WJ, et al. Molecular basis for manganese sequestration by calprotectin and roles in the innate immune response to invading bacterial pathogens. Proc Natl Acad Sci USA 2013;110: 3841-6.

10. World Health Organization; Regional Office for the Western Pacific; International Diabetes Institute; International Association for the Study of Obesity; International Obesity Task Force. The Asia-Pacific perspective: redefining obesity and its treatment. Sydney: Health Communications Australia; 2000.

11. Korea Centers for Disease Control and Prevention; The Kore- 
an Pediatric Society; The Committee for the Development of Growth Standard for Korean Children and Adolescents. 2017 Korean children and adolescents growth standard (commentary for the development of 2017 growth chart). Cheongju: Korea Centers for Disease Control and Prevention; 2017.

12. Mendall MA, Chan D, Patel R, Kumar D. Faecal calprotectin: factors affecting levels and its potential role as a surrogate marker for risk of development of Crohn's Disease. BMC Gastroenterol 2016;16:126.

13. Upadhyay J, Farr O, Perakakis N, Ghaly W, Mantzoros C. Obesity as a disease. Med Clin North Am 2018;102:13-33.

14. Hotamisligil GS, Arner P, Caro JF, Atkinson RL, Spiegelman BM. Increased adipose tissue expression of tumor necrosis factor-alpha in human obesity and insulin resistance. J Clin Invest 1995;95:2409-15.

15. Ding S, Lund PK. Role of intestinal inflammation as an early event in obesity and insulin resistance. Curr Opin Clin Nutr Metab Care 2011;14:328-33.

16. Poullis A, Foster R, Shetty A, Fagerhol MK, Mendall MA. Bowel inflammation as measured by fecal calprotectin: a link between lifestyle factors and colorectal cancer risk. Cancer Epidemiol Biomarkers Prev 2004;13:279-84.

17. Verdam FJ, Fuentes S, de Jonge C, Zoetendal EG, Erbil R, Greve JW, et al. Human intestinal microbiota composition is associated with local and systemic inflammation in obesity. Obesity (Silver Spring) 2013;21:E607-15.
18. Spagnuolo MI, Cicalese MP, Caiazzo MA, Franzese A, Squeglia V, Assante LR, et al. Relationship between severe obesity and gut inflammation in children: what's next? Ital J Pediatr 2010;36:66.

19. Li F, Ma J, Geng S, Wang J, Liu J, Zhang J, et al. Fecal calprotectin concentrations in healthy children aged 1-18 months. PLoS One 2015;10:e0119574.

20. Davidson F, Lock RJ. Paediatric reference ranges for faecal calprotectin: a UK study. Ann Clin Biochem 2017;54:214-8.

21. Song JY, Lee YM, Choi YJ, Jeong SJ. Fecal calprotectin level in healthy children aged less than 4 years in South Korea. J Clin Lab Anal 2017;31:e22113.

22. Lee YM, Min CY, Choi YJ, Jeong SJ. Delivery and feeding mode affects fecal calprotectin levels in infants $<7$ months old. Early Hum Dev 2017;108:45-8.

23. Hawley NL, Johnson W, Nu'usolia O, McGarvey ST. The contribution of feeding mode to obesogenic growth trajectories in American Samoan infants. Pediatr Obes 2014;9:e1-13.

24. Andersson Y, Hammarström ML, Lönnerdal B, Graverholt G, Fält $\mathrm{H}$, Hernell O. Formula feeding skews immune cell composition toward adaptive immunity compared to breastfeeding. J Immunol 2009;183:4322-8.

25. Halvorson EE, Ervin SE, Russell TB, Skelton JA, Davis S, Spangler J. Association of obesity and pediatric venous thromboembolism. Hosp Pediatr 2016;6:22-6. 